atendance as a precedent, and only have sought his attendance when a case was really urgent. This is, indeed, the only public recognition we get for our charity; the more we exercise it the more we are obliged to, or else stand the chance of being called inhumane liy a coroner's jury.

The remuneration of the profession generally now is most inadequate, and the work such that the ordinary medical man is never at rest night or day. I think, therefore, the professional journals should do everything in their power consistent with fairness to uphold him.

September, 1890. I am, Sirs, yours truly,

* * We insert ** We insert the above letters. It cannot be too well whrow jauntily on the medical profession the weight of dealing with urgent diseases of the poor, with little praise when they do their beneficent work and plenty of abuse if they fail. We are still of opinion that Mr. Connan should have continued his attendance on the patient he saw, at least until the Poor-law medical officer was in full charge. But for such a case to fall between the two stools of a provident association and the parish was a sad miscarriage of benevolence. It is no reply to say that the censuring jury would not have put their hands into their pockets to pay the doctor's fees. So much the worse for the jury. Perhaps if they had seen the patient, which is the case of the medical man, they would have been moved to this effect. Whether or not, medical znen must be guided by their own deep lights and by the traditions of the profession.-ED. L.

\section{SUSPENSION IN LOCOMOTOR ATAXY.}

\section{To the Editors of THE LANCET.}

SIRS,-In THE LANCET for August 9th, 1890, an article appeared on the above subject, in which the opinion is expressed that before long the suspension apparatus will be relegated to obscurity, along with Perkin's metallic tractors of a past generation \&c. It is also stated that Rosenbaum recently brought before the Berlin Medical Society the result of the treatment of 85 cases treated in Mendel's clinique, with improvement in 25 only.

Now, if this latter statement were strictly accurate, it would yet show improvement in 29 per cent. of the cases of a malady which is acknowledged to be most intractable; and this could hardly be considered a very bad result. It appears, however, from Rosenbaum's paper, which is published in extenso in the Deutsche Medicinische Wochenschrift for Sept. 13th, 1890, that the treatment had had a fair trial only in 61 cases of locomotor ataxy, as, out of the 85 treated altogether, 9 patients were suffering from other diseases, and 15 affected with tabes were -only treated for such a short time that their cases could not be utilised. Out of these 61 cases 25 were improved, which gives the higher rate of 40 per cent., and this is probably as good as that obtained by any other mode of treatment of tabes taken by itself. In all these cases no medicine was igiven, so that the objection of your reviewer, "that a number of the cases reported appeared to have been actively treated by drugs such as iodide of potassium whilst undergoing suspension," does certainly not ap aly to the practice of Mendel. Theopinion of your reviewer "that the improvement observed is in the main due to the mental effect produced by the novelty of the method and the imposing apparatus employed "-an opinion previously expressed by Hanshalter and Adam of Nancy-is not shared by Rosenbaum, who states that the effects of suggestion may have been called into play at Nancy, but were certainly not so at Berlin. It is notorious that in the latter city the population, and more especially those strata of it which furnish the hospital patients, have always been remarkable for a highly developed ritical faculty, which would not befavourable for suggestion being particularly active there. In connexion with this I may draw your readers' attention to a paper on the same subject by Dr. Allan Maclane Hamilton, which appears in the New York Medical Record for Aug. 30th, 1890, and in which the conclusion is expressed that the suspension treatment "certainly effects decided amelioration of all the symptoms of tabes, excepting the lost knee-jerk and ocular degenera- tion." Dr. Hamilton gives the details of five well-marked cases of tabes in which decided improvement was caused by this treatment. In these cases likewise no medicine had been given. Suspension will probably survive the destructive criticism which bas been directed against it. I am, Sirs, yours faithfully,

Harley-street, September, $1890 . \quad$ JuliUs ALTHAUS, M.D.

\section{PICROTOXIN AND ITS USES.}

\section{To the Editors of THE LANCET.}

SIRS, - The recommendation of picrotoxin for admission into the forthcoming Addendum to the British Pharmacopoeia has once more directed attention to a useful but much-neglected remedy. Although isolated by Boullay as far back as 1812-six years before the discovery of strychnine, -it has of late failed to maintain its position as a therapeutic agent, its name not appearing once in the indexes to the volumes of THE LANCET for the last ten years. It is official in the United States and in the French Pharmacopoias, but not in the others. As it is not an alkaloid, it will presumably be introduced into our Pharmacopoia under the name of picrotoxinum, in accordance with the system of nomenclature adopted in the case of other neutral principles, such as elaterinum, santoninum, and salicinum. It will probably be defined as a neutral principle prepared from the seeds of anamirta paniculata, the cocculus indicus plant. It has been found that cocculus Plukenetii and cocculus lacunosus contain the same principle, but it is hardly likely that they will be recognised as official sources. Whether the cocculus indicus seeds themselves - the old coccole di Levante-will be introduced into the Pharmacopoi $x$ remains to be seen.

It is somewhat doubtful whether picrotoxin is or is not a simple body. Barth and Kretschy assert that it is a mixture of three different substances, which they name "picrotoxin" (a bitter poisonous principle), "picrotin" (a bitter nonpoisonous principle), and "anamirtin." Paternò and Oglialoro question the correctness of these statements, and assert that "picrotoxin" and " picrotin" are merely decomposition products. They object strenuously to the new use of the term "picrotoxin," and rename the picrotoxin of Barth and Kretschy "picrotoxinin," to distinguish it from the true picrotoxin contained naturally in cocculus indicus. They also take objection to the "picrotin," which they believe to be identical with a substance named by them "hydrate of picrotoxide." As to anamirtin, they simply deny its existence in pure picrotoxin, and state that it is never found when the drug is purified by repeated crystallisation. Schmidt and Löwenhardt confirn. the observations of Paterno and Oglialoro, but they have somewhat complicated matters by discovering a new active principle which they provisionally name " cocculin." Their opponents, however, are disinclined to admit the validity of their claims, and assert that cocculin is only anamirtin under another name. Whether picrotoxin is or is not a simple substance is a matter of very little importance from a purely pharmacopœial point of view, for it is well known that digitalin, which was at one time official, was composed of quite a collection of neutral principles. Moreover, atropine, like the other mydriatic alkaloids, is not a simple body, but can be resolved into tropine and tropic acid.

Picrotoxin has well-marked physical characters, and is usually met with in the form of colourless feathery crystals having an intensely bitter taste. It is soluble in water in the proportion of 1 in 240 at a temperature of $60^{\circ} \mathrm{F}$., but the solution is not stable, for when the temperature falls below $40^{\circ}$ nearly half of it crystallises out. It is much more readily soluble in a mixture of acetic acid and water, and it is to be hoped that a liquor picrotoxini made with acetic acid will be rendered official. Picrotoxin does not form salts, and it is the picrotoxin itself which is employed.

Fortunately, the pharmacological action of picrotoxin has been thoroughly worked out, and we deal with a substance having a very definite physiological action. The peculiar convulsions produced by it in the lower animals were accurately described by Glover more than forty years ago. They differ essentially from the tetanic condition caused by strychnine, and are due to stimulation of the motor centres in the cerebrum, or in the medulla and cord.

It is a curious fact that most of our writers on therapeutics are silent on the subject of picrotoxin. Wood, for example, does not mention it, and Ringer refers to it only 
incidentally. Bartholow gives a good summary of its uses, but the most exhaustive account is to be found in Phillips' well-known "Vegetable Kingdom." Planat and Ilammond recommended it in epilepsy, and Gubler proposed its use in chorea. Phillips lays down definite rules for its employment in various complaints-notably in certain forms of dyspepsia, megrim, and dysmenorrhoea. Externally, it is used in the form of a pigment or paint as a parasiticide. I have employed it largely in closes of $\frac{1}{t}$ th of a grain in the treatment of the night sweating of phthisis, for which it is an excellent remedy. It probably acts as an anhidrotic by stimulating the respiratory centre.

There seems to be some difference of opinion as to the dose ; in a well-known Dictionary of Medicine it was stated to be $\frac{1}{6}$ th of a grain, but this was subsequently corrected and was obviously a misprint. I believe the correct dose is from $\frac{1}{12}$ th to $\frac{1}{60}$ th of a grain. In the Pharmacopoia of the Westminster Hospital we have a pill containing $\frac{1}{5}$ th of a grain made with sugar of milk and glycerine of tragacanth, and I have never given more than two of these three times a day. Crichton Browne finds that in rabbits the toxic dose is th of a grain to the pound, and in guinea-pigs about 1 th of a grain to the pound. There are very few cases of poisoning on record. Many years ago several men suffered severely from drinking rum impregnated with cocculus indicus, and one of them died. In another case, a boy aged twelve died from swallowing forty grains of a fish poison containing cocculus indicus, but the strength of the preparation was not known. There might possibly be some difficulty in detecting with certainty the presence of picrotoxin in the dead body, for Giacomelli has described a ptomaine closely resembling it both in physical characters and chemical reactions. The pharmacological actions would probably serve to differentiate them. Picrotoxin is allied to cicutoxin-the active principle of the water-hemlock-and to coriamyrtin, derived from coriaria myrtifolia. These drugs stimulate the origins of the inhibitory fibres of the vagus, the vascular and respiratory centres, and the motor areas of the medulla oblongata. In its action on the secretions, picrotoxin is allied to pilocarpine and muscarine, and is antagonised by atropine and members of that group. The best antidote to picrotoxin is chloral hydrate. - I am, Sirs, your obedient servant, William MurReli, Weymouth-street, Sept. I5th, 1890 Lecturer on Pharmacology at the

\section{"INTERNATIONAL CONSUMPTION OF MEAT." To the Editors of THE LANCET.}

SIRS,-Dr. Yorke-Davies's remarks are interesting. Last year Dr. G. Herschell, writing on a diet of lean meat, raised a momentous question. You were good enough to publish my reply, which I hoped would have the effect of raising an interesting discussion and eliciting from some of our well-known physiologists an alteration of their views. I most emphatically venture to point out that the rules of diet laid down by the late Professor Parkes, Sir Lyon Play. fair, and others require to be altered; in fact, they are entirely misleading and out of date. From an experience of over 400 cases of obesity I have had under my care, many of them extremely weighty and bulky, I confidently assert that a pure nitrogenous diet, largely diluted, is not only safe, but beneficial in all ways. Dr. Yorke-Davies was the first to say my diet was fraught with extreme danger and Spartan in the extreme. Well, I am glad to say that he has entirely changed his views, practises my system almast verbatim, and is therefore beginning to get some good results, upon which I congratulate him heartily. When I began the treatment of obesity I thought to lay down a set of diet rules that would suit everyone. I soon found out my error. A 20 st. man or woman requires longer and more vigorous treatment than those of more moderate weight. Every week I have something new to learn, and so regulate my diet to suit each individual case. Age, family history, state of general health, all have to be carefully weighed and considered. A lady aged thirtynine, weight 16 st. $4 \mathrm{lb}$, and abdominal girth $49 \mathrm{in}$, in good health, excepting heart and lungs overtaxed, began treatment on Aug. 20th. I saw her on the 28 th. She lost in weight $93 \mathrm{~s}$. and 7 in. in girth, and expressed herself as being better and able to get about, and felt her health greatly improved. I do trust that some competent physiologist will ventilate in your journal Dr. Herschell's query.
For my own part, I endorse Dr. Yorke-Davies's remarks. Apologising for taking up so much space,

I am, Sirs, yours obediently,

Devonshire-street, w., Sept. 2nd, 1890. W. TOWERS SMTTH,

\section{To the Editors of THE LANCET.}

Sins, - Your correspondent, Mr. Henderson, has to go a long way back - to the time of the ancient Greeks and Romans - for theories to controvert what he is pleased to call my illogical letter, and he confesses his ignorance of the dietetics even of those nations with whose prowess he is $s 0$ familiar. As far as my knowledge of their history goes, always understood that their conquests were celebrated by feasts, and Heliogabalus was such a gourmand in the way of flesh food that his favourite dish consisted of peacock's brains and other epicurean delicacies. In the period of their decline, for aught I know, and I think it is quite likely, they may have taken to "porridge" which $\mathrm{Mr}$. Henderson eulogises so highly. I wish MIr. Henderson would bring a few facts forward to controvert my argument If he could prove that nitrogenous food makes people fat and heavy, and that the Chinese who do not eat any flesh food are more energetic and brave than the English people who do, or that those Bralımins who live entirely on vegetable food become so obese and stupid as to be a byword, I should almost believe he was right in his con. tention.

If sex even can be altered by food, as in the case of the queen bee, surely it is not impossible that food may have much to do with the deterioration of certain races. I do not imagine that even your correspondent will argue that the climate or soil of Greece or Italy has altered within the las two thousand years. Then why has the race deteriorated?"

$$
\text { "Tis Greece, but living Greece no more." }
$$

The solution is most likely to be found in their dietetics, for I imagine no one will argue that the Greeks with whom Alexander overran the world, or that the Romans whom Ciesar so often led to victory, resemble the Greeks and Romans of the present day. Bears, lions, and other wild animals become comparatively tame if fed on farinaceous foods, and I question if the athlete would be as well developed if he lived on pap and stewed apples.

Pavy, in his work on Dietetics, illustrates the truth of my argument that flesh food gives more energy than farinaceous when he instances the case of the English and French navvies. During the construction of a railway in France it was found that an English navvy did a thiro more work a day than his French brother. Inquiry elicited the fact that the Englishman ate more meat and the French. man more haricots and vegetable food. They were both put on the same rations, and the irregularity vanished.

The great evil, as I pointed out in my former letter, of excess in farinaceous food is the difficulty of eliminating it, and its proneness to remain in the system stored as fat and other products of retrograde metamorphosis. Your correspondent makes light of this ; but it is no laughing matter to tens of thousands to whom it makes life a burden. I rejoice to think that in lean meat, with a little ballast in the way of vegetables tolerably free from starch and sugar, we have a means of quickly getting rid of this too common encumbrance, and at the same time gaining in energy, comfort, and length of life. I presume Mr. Henderson will not deny that farinaceous food is more prone to induce obesity than meat food, and that an obese person is not as energetic and active as a lean one, and that carrying from two to ten stone more than is necessary of adipose tissue does not tend to make a man more robust, mentally or bodily.

Until your correspondent tells us what the "other more important factors which contribute towards the formation of racial characteristics" are, I fear I shall still go on believing in Pavy, history, common sense, facts, and daily observation, rather than in the crude theories and "porridge" of Mr. Henderson. - I am, Sirs, yours faithfully,

Sherborne, Sept. 14th, $1890 . \quad$ N. E. YORKE-DAVIES.

\section{THE VALUE OF THE DIAZO REACTION} To the Editors of THE LANCET.

Srns,-In your issue of Aug. 23rd is a synopsis of eases in which Dr. Riitimeyer tested the urines for the so-called diazo reaction (with sulphanilic acid and sodic nitrite). When house physician at St. Bartholomew's Hospital this 